\title{
Real-Time Monitoring of Trace Gas Concentrations in Syngas
}

\author{
J. Herbig' , R. Gutmann ${ }^{1}$, K. Winkler ${ }^{1 *}$, A. Hansel ${ }^{1,2}$ and G. Sprachmann ${ }^{3}$ \\ 1 lonimed Analytik GmbH, Eduard-Bodem-Gasse 3, 6020 Innsbruck - Austria \\ 2 Institute of Ion Physics and Applied Physics, Leopold-Franzens University Innsbruck, Technikerstrasse 25, 6020 Innsbruck - Austria \\ 3 Shell Global Solutions International BV, Researcher Gas Separation Technologies, Amsterdam - The Netherlands \\ e-mail: jens.herbig@ionimed.com - rene.gutmann@ionimed.com - klaus.winkler@ionimed.com \\ armin.hansel@uibk.ac.at gerald.sprachmann@shell.com \\ * Corresponding author
}

\begin{abstract}
Résumé - Suivi en temps réel des concentrations de gaz traceurs dans un extrait de gaz de synthèse Un spectromètre de masse par réaction de transfert de protons (PTR-MS, Proton Transfer Reaction - Mass Spectrometer) a été utilisé pour l'analyse de gaz de synthèse dans un procédé industriel Fischer-Tropsch. Un PTR-MS peut détecter une grande variété de composés organiques et inorganiques volatils en temps réel et avec une sensibilité élevée. Associé à un multiplexeur, il permet un suivi en ligne (en temps réel) des contaminants à l'état de traces à différents stades d'un procédé Fischer-Tropsch. Plusieurs composés volatils, tels que $\mathrm{HCN}, \mathrm{H}_{2} \mathrm{~S}, \mathrm{RSH}$, des carbonyles, des acides, des alcools et autres, ont été mesurés dans du gaz de synthèse. Cet article décrit la configuration pour le suivi du gaz de synthèse en utilisant le PTR-MS et résume le résultat de ce projet de preuve de concept.
\end{abstract}

\footnotetext{
Abstract - Real-Time Monitoring of Trace Gas Concentrations in Syngas - A Proton Transfer Reaction Mass Spectrometer (PTR-MS) was used for the analysis of syngas in an industrial Fischer-Tropsch process. A PTR-MS can detect a variety of volatile organic and inorganic compounds in real-time and with high sensitivity. Together with a multiplexer, this allows for online (real-time) monitoring of the trace contaminations at different stages of a Fischer-Tropsch process. Several volatile compounds, such as $\mathrm{HCN}, \mathrm{H}_{2} \mathrm{~S}, \mathrm{RSH}$, carbonyls, acids, alcohols and others have been measured in syngas. This paper describes the setup to monitor syngas using PTR-MS and summarizes the result of this proof-of-principle project.
} 


\section{INTRODUCTION}

In industrial gas processes the knowledge about the exact composition of the gases is important and is closely monitored and controlled. Beside the main constituents which typically appear in the percent concentrations, also trace gas impurities at much lower concentrations can play a crucial role. For example, silico-organic compounds are converted to silicon oxide in gas combustion, which result in an increased maintenance [1] and potentially in the deactivation of an exhaust gas catalytic converter. Another example, the catalytic activity of most transition metals is drastically reduced by the presence of sulfur-containing compounds at extremely low concentration. This poisoning effect is a major problem in many catalytic reactions, especially hydrogen reactions such as methanation of coal synthesis gas or reforming of naphthas [2]. Furthermore, when large amounts of off-gas are being released, also trace concentrations of compounds of extreme toxicity constitute an environmental risk.

A Proton Transfer Reaction Mass Spectrometer (PTR-MS) [3, 4] is a gas analytical device for the sensitive detection of volatile organic compounds. These devices are well established in several fields of research where their capability to analyze samples in real-time yields insights into the dynamic of the system. Prime examples where PTR-MS technique is extensively used for VOC analysis are environmental [5, 6] food and flavour $[7,8]$ and medical $[9,10]$ applications. Recently, this method is extended to monitor drugs and explosives $[11,12]$. Broad application for industrial process monitoring however is not common so far [13-15]. Moreover, the analysis of sample gas via PTR-MS is predominantly focussed on the analysis of volatile organic compounds in a matrix of air.

The objective of this project was the real-time monitoring of trace gas compounds in syngas at different process steps. In this paper, we demonstrate the extension of the PTR-technique to the monitoring of trace compounds in an industrial Fischer-Tropsch gas process. This is new in several ways. First, the matrix consists of syngas (mixture of $30 \% \mathrm{H}_{2}$ and $70 \%$ of CO) [16]. Second, beside some organic compounds, there is a high interest in the monitoring of inorganic and organo-metallic trace compounds in syngas. Finally, the gas composition of several steps in the process have to be monitored in parallel and in an automated fashion, thus a multiplexer was integrated into the setup.

We have employed PTR-MS instruments in several installations in a Fischer-Tropsch process operated by Shell Global Solutions (SGS) to monitor trace concentrations in syngas. In this paper, we describe this application and give an overview over the main volatile organic and inorganic compounds that can be observed and the concentration ranges that can be expected. In many PTR-MS applications, mainly organic compounds such as methanol, acetone or benzene, are measured routinely, whereas the measurement of compounds, such as hydrogen sulfide, methyl-mercaptan, metal carbonyls, has not been reported so far. Here, we will summarize the optimization of the measurement of the main compounds. We have performed calibrations, which allow a determination of the sensitivity for specific compounds. We assess also the limits of detection of setup and instrument and discuss the restrictions and potential improvements.

\section{MATERIALS AND METHODS}

The heart of the experiment was a Proton Transfer Reaction Mass Spectrometer (PTR-MS) system, which was installed in an industrial gas processing site for continuous monitoring of trace gas compounds in different processing steps.

In standard applications the PTR-MS sample gas inlet is directly connected to the gas stream. For the present application several modifications were necessary. Both main constituents of syngas ( $\mathrm{CO} 70 \%$ and $\mathrm{H}_{2} 30 \%$ ) pose substantial (health) risks. Therefore, the PTR-MS was connected to a closed gas system, i.e. the exhaust of the PTR-MS has to be connected to the off-gas stream of the installation, see Figure 1. Unless otherwise stated, all sample gas carrying lines are treated with Silconert ${ }^{\mathrm{TM}} 2000$ [17] to make them inert in order to avoid surface adsorption.

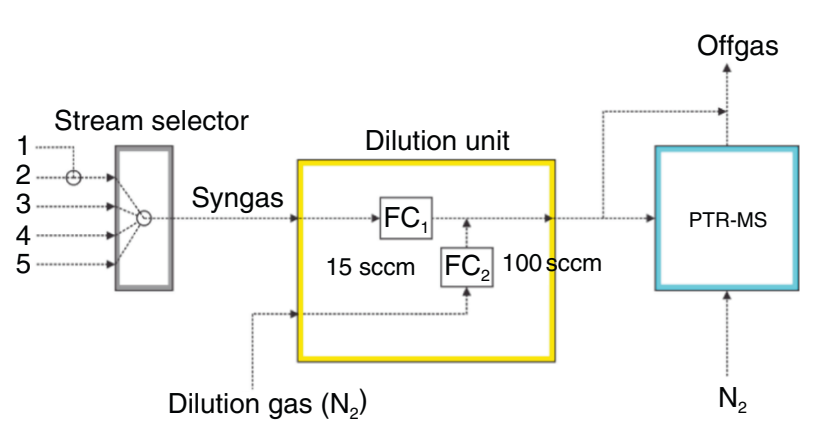

Figure 1

Schematic of the setup for the monitoring of process gas. Different streams can be selected by the stream selector. Typically, in the dilution unit $15 \mathrm{sccm}$ of the process gas were diluted with $100 \mathrm{sccm}$ of $\mathrm{N}_{2}$. Approximately $80 \mathrm{sccm}$ of the diluted gas were drawn into and analyzed by the PTR-MS. 


\subsection{PTR-MS}

We have used a high-sensitivity PTR-MS system (Ionicon Analytik GmbH, Innsbruck, Austria). The principles of operation of PTR-MS are extensively described elsewhere [3], specifications are listed in [18].

The PTR-MS has been slightly modified: in order to ensure the tightness of the system even in the event of back-pressure from the off-gas line, the exhaust water trap has been removed. To efficiently prevent condensation of water (from sample gas or the ion source) in the pump or exhaust, dry nitrogen $(0.5-1 \mathrm{~L} / \mathrm{min})$ has been used.

Initially, we have performed scans ranging from $m / z 20 \mathrm{Th}$ (ion mass-to-charge ratio) ${ }^{1}$ to $m / z 200 \mathrm{Th}$ in order to screen for significant signals. For the continuous monitoring, we have selected several $\mathrm{m} / \mathrm{z}$ (MID mode), which were composed of the compounds of interest, their isotopes and potentially fragments and other signals that appeared significant in the scans. The typical dwell time per $m / z$ was set to $1 \mathrm{~s}$.

The PTR-MS was operated at the following parameters: drift pressure of 2.2 mbar and a drift voltage of $400 \mathrm{~V}$. After initial tests with different drift voltages, this voltage was chosen for good sensitivity for several compounds and little fragmentation. The temperature of the reaction chamber was kept at $80^{\circ} \mathrm{C}$. The sample gas inlet line connecting the PTR-MS and the dilution unit was also heated to $80^{\circ} \mathrm{C}$, although everything else upstream was at room temperature. In this application, the sample gas dew point was held at $20^{\circ} \mathrm{C}$ with a pressure of 2 bar (a) before it enters into the Fischer-Tropsch process.

\subsubsection{Dilution}

By using a sample gas dilution system, the range for linear signal response in the PTR-MS (normally $\sim 10 \mathrm{ppt}$ to $10 \mathrm{ppm}$ ) can be shifted upwards to optimize for the current conditions. In the dilution unit, see Figure 1, a mass flow controller (FC1) restricts the process gas flow to $15 \mathrm{sccm}$ (standard cubic centimeter per minute). These $15 \mathrm{sccm}$ were diluted with $100 \mathrm{sccm}$ of clean $\mathrm{N}_{2}$ (controlled by FC2), resulting in a dilution ratio of $15: 100$ $(\times 6.67)$. The PTR-MS draws about $80 \mathrm{sccm}$ of the gas mix, the excess gas goes into the off-gas line. The dilution was necessary for several reasons. First, high concentrations of some compounds were observed in several of the streams, which were close to the upper limit of linearity of the PTR-MS. If this limit is reached for one com-

\footnotetext{
${ }^{1}$ Due to the proton-transfer reaction, the charge is always 1 and the mass of the ion (protonated mass) is always $1 \mathrm{u}$ higher than that of the compound. The $m / z$ is usually given in Th (Thomson), which is sometimes omitted.
}

pound, the linearity of the measured signal of all other compounds would also be compromised. Second, the composition of the sample gas matrix can have a significant influence on the kinetics of the ionization reaction. A gas matrix consisting mainly of $\mathrm{N}_{2}$ ensures constant conditions and the comparability to other measurements, e.g. calibrations where $\mathrm{N}_{2}$ was used as a dilution gas. Finally, through dilution, the high $\mathrm{H}_{2}$ concentration can be lowered to reduce the risk of explosion and to avoid a depreciation of the desired vacuum in the instruments detection region, due to the lower pumping efficiency of the turbo molecular pumps for hydrogen. The dilution was accomplished with an adapted version of the ionimed Gas Calibration Unit (GCU) [19]. This had the advantage that the dilution could be controlled by software.

\subsubsection{Data Normalization}

All data have been processed according to standard practice in PTR-MS measurements, i.e. the raw data have been normalized to 1 million cps (counts-per-second) of primary ions $\left(\mathrm{H}_{3} \mathrm{O}^{+}\right.$, actual number of primary ions $\sim 20$ million cps), resulting in instrument-independent "normalized counts-per-second" (ncps). The instruments sensitivity, determined in calibration experiments, has been used to convert measured signals in units of parts-per-billion by volume (ppbv). Therefore a correction for the instruments transmission function was not necessary. As a final step, the dilution factor has been accounted for to get the undiluted concentrations in the gas streams.

\subsubsection{Stream Selector}

A PTR-MS constantly draws and analyzes sample gas. In order to measure at several points in the process in parallel, the inlet sample gas stream has to be multiplexed. This means that several streams (each drawn from a certain point in the process) have to be alternately connected to the PTR-MS's inlet, which poses new challenges. When streams are switched, an instantaneous change of concentrations is expected and therefore the shared part of the sampling line needs to consist of inert material in order to minimize carry-over effects. Also, when switching to a sampling line, the flow and pressure in this line should not be changed. For switching, we have used a multiplexing valve (stream selector, in Fig. 1) that was already installed in the process. This device has four ports, of which three are connected to different points in the process, see below, and one to calibration gas standards. In the following, we indicate the streams by numbers, indicating their position in the process, i.e. stream 4 is downstream of stream 3 , and so forth. 


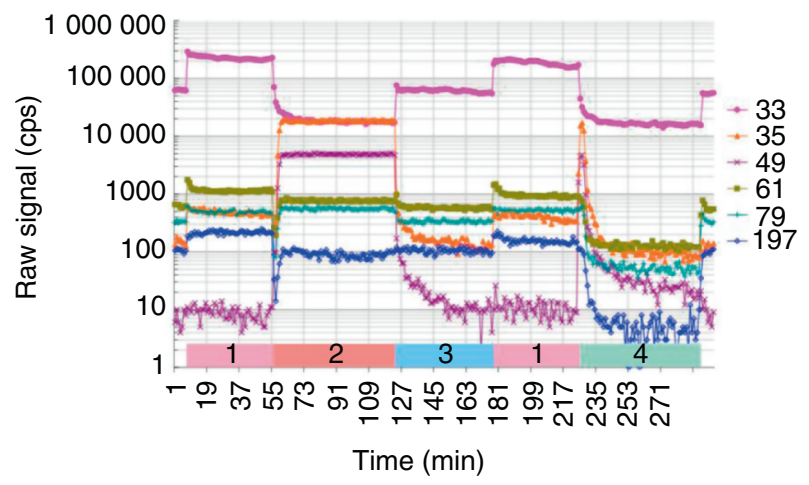

Figure 2

Typical raw signal data measured with the PTR-MS. The streams have been identified with the sequence of the stream selector.

\subsubsection{Data Selection}

In the simple setup, the stream selector was programmed to switch between the different sampling streams on a periodic basis (every hour) while the PTR-MS measured continuously. In this setup, an additional manual valve was operated to alternate between streams 1 and 2 .

As can be seen from Figure 2, the switching between streams is clearly visible in the signals. By comparing to the sequence of the stream selector, we could attribute every data block (between switches) to the corresponding stream. Data points taken immediately after switching were omitted to account for carry-over effects. The visible carry-over-effect we mainly attributed to the shared part of the sample line and most importantly to the inner surface of the flow controller - the only party consisting of uncoated stainless steel. The remaining data (last 20 data points) in one block have been averaged to represent one data point.

We have performed regular measurements of the background in the pure $\mathrm{N}_{2}$ dilution gas. This background (typically low) has been subtracted. In the case of overlapping signals (see Sect. 2.3), we have performed additional corrections.

\subsubsection{Calibration}

In principle, in PTR-MS measurements the sensitivity can be calculated since the underlying mechanism is simple: when a compound has a proton affinity higher than that of $\mathrm{H}_{2} \mathrm{O}$, i.e. $>165 \mathrm{kcal} / \mathrm{mol}(691 \mathrm{~kJ} / \mathrm{mol})$, then ionization via proton transfer happens in the reaction chamber at every collision with a precursor ion $\left(\mathrm{H}_{3} \mathrm{O}^{+}\right)$[3]. Typically, this method delivers results with an accuracy of better than $50 \%$. Not included in this simple model are different reaction kinetics or fragmentation of a compound. In contrast, in a calibration experiment all necessary parameters are included. We have therefore calibrated the PTR-MS system for most of the compounds of interest, such as $\mathrm{H}_{2} \mathrm{~S}, \mathrm{HCN}$, Fe- and Ni-carbonyl, and a series of VOC (volatile organic compounds), see below.

In order to calibrate the instruments, calibration gas standards were connected to the stream selector. Using the flow controllers in the dilution unit different mixing ratios could be set in order to get a calibration curve. We have performed multi-point calibrations or "quick" calibrations, which consist of only two steps: a background measurement and one mixing ratio at moderate concentrations. This already delivers sufficiently accurate results, since the signal response of the PTR-MS is linear over several orders of magnitude.

The following gas standards were used: a multi component gas standard (Apel Riemer Inc., USA, custom made VOC mix) containing 17 VOC with approximately $1 \mathrm{ppm}$ in $\mathrm{N}_{2}$ of methanol, acetonitrile, acetaldehyde, ethanol, acroleine, acetone, benzene and others. For the compounds $\mathrm{Fe}(\mathrm{CO})_{5}, \mathrm{Ni}(\mathrm{CO})_{4}, \mathrm{HCN}$ and $\mathrm{H}_{2} \mathrm{~S}$, several separate standards (Linde gas) in different concentrations were used. Typically the accuracy of the concentrations was $5 \%$.

\subsubsection{Limit of Detection (LOD)}

The LOD is the signal intensity, which is significantly $(3 \sigma)$ above the background noise level. The background noise can be determined in blank measurements, which were performed on a regular basis. In the employed system, we have several sources for background noise:

- electrical background (in PTR-MS detector dark counts),

- chemical noise (e.g. contaminations in the $\mathrm{N}_{2}$ dilution gas),

- cross-talk between streams (insufficient equilibration after switching),

- overlap on the mass of interest from other compounds.

Typically PTR-MS instruments have very low inherent electronic and chemical background. The largest background in a blank measurement in this setup is given (for most compounds) by the chemical background: either remnant contaminations in the gas line (cross-talk) or contamination in the $\mathrm{N}_{2}$ gas used for dilution. As an example, in Nitrogen 6.0 there can be still $100 \mathrm{ppb}$ of hydrocarbons. Thus, it makes sense to differentiate different LOD.

\section{Method LOD}

This LOD has to be determined experimentally. It is certainly an upper limit for the LOD. It includes all 
possible noise sources and reflects the whole setup, lining system, flow controller, cross-talk after the stream selector and the (long term) background variation over the whole course of the experiment. Also the dilution factor and data evaluation steps are included in this LOD.

\section{Instrument LOD}

The measured instrument LOD has been determined in the calibration measurements and still includes the chemical noise in the dilution gas. In contrast to the method LOD, the blank sample has been measured with longer flushing times of the lines.

\section{Achievable LOD}

We also estimate the LOD that would be possible in an ideal setup, i.e. in the absence chemical background noise, without dilution and with long integration time. This LOD only includes the measured electronic noise of the instrument and the measured sensitivity (for 10 seconds integration time).

\section{RESULTS AND DISCUSSION}

In a first step, we have performed repeated scans over all gas streams to determine where significant signals are to be expected. From over 200 measured $\mathrm{m} / \mathrm{z}$, we find approx. $123 \mathrm{~m} / \mathrm{z}$ for which the highest observed concentration (maximum over all gas streams) where significantly above the background and at least above $\sim 50$ ppt. From these, we have selected several compounds of interest, which are presented in Table 1.

\subsection{Calibration and LOD}

A typical calibration plot is depicted in Figure 3. The PTR-MS ncps-signal is plotted versus the concentration, which has been calculated taking the original concentration in the employed gas standard and taking into account the flows of the mass-flow controllers FC1 and FC2 from Figure 1.

The slope of the calibration plot is the sensitivity of the PTR-MS for this compound and is used to convert measured data to concentrations. The data measured at $0 \mathrm{ppb}$, gives the instrumental background (usually low) and the noise in this data determines the LOD, as described above. Table 2 summarizes sensitivities and LOD of relevant compounds. The sensitivity depends on the instrumental settings, which were kept constant throughout all measurements. Also, the gas matrix can
TABLE 1

Listed are $m / z$ with prominent signal intensities, mostly we give the tentatively identified compound, typically backed-up by the isotopic ratio. The average concentration ranges observed (over time and over sampling points) are represented by logarithmic categories ranging from o $(<0.3 \mathrm{ppb})$, oo $(<3 \mathrm{ppb})$, ooo $(<30 \mathrm{ppb})$, to ooooo ( $>300 \mathrm{ppb}$ range)

\begin{tabular}{|c|c|c|}
\hline$m / z(\mathrm{Th})$ & $\begin{array}{c}\text { Concentration } \\
\text { range }\end{array}$ & Potential compound \\
\hline 28 & o & $\mathrm{HCN}$ \\
\hline 33 & 00000 & Methanol \\
\hline 35 & ooo & $\mathrm{H}_{2} \mathrm{~S}$ \\
\hline 42 & o & Acetonitrile \\
\hline 43 & oo & $\begin{array}{c}\text { Acylium fragment } \\
\text { (from e.g. } \\
\text { isopropanol) }\end{array}$ \\
\hline 47 & oo & Formic acid \\
\hline 49 & ooo & Methyl mercaptan \\
\hline 51 & ooo & $\begin{array}{l}\text { Methanol water } \\
\text { cluster }\end{array}$ \\
\hline 57 & o & Acroleine \\
\hline 59 & o & Acetone \\
\hline 61 & ooo & Acetic acid \\
\hline 105 & oo & $\begin{array}{l}\mathrm{Ni}(\mathrm{CO}) \mathrm{H}_{3} \mathrm{O}+\text { (main } \\
\text { fragment of Ni } \\
\left.(\mathrm{CO})_{3} \mathrm{H}^{+}\right)\end{array}$ \\
\hline 143 & oo & $\mathrm{Ni}(\mathrm{CO})_{3} \mathrm{H}^{+}$ \\
\hline 197 & oo & $\mathrm{Fe}(\mathrm{CO})_{5} \mathrm{H}^{+}$ \\
\hline
\end{tabular}

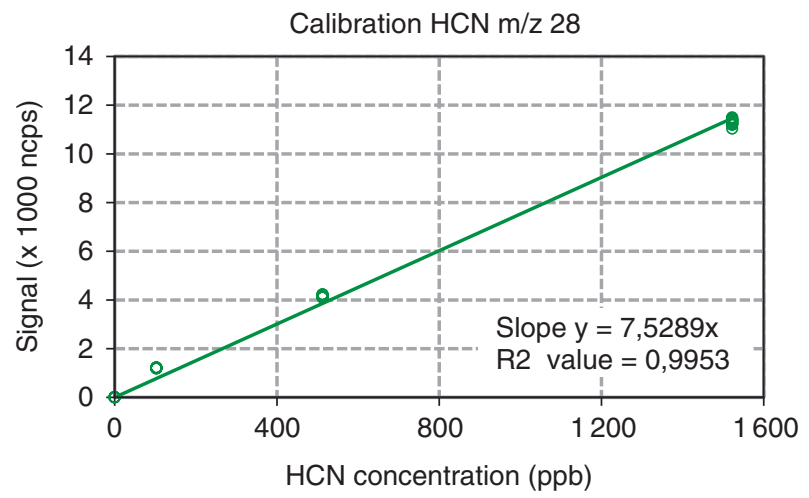

Figure 3

A typical calibration curve. As example $\mathrm{HCN}$ is shown.

have an influence [20]. In the calibration experiments, the matrix was pure $\mathrm{N}_{2}$. However, we do not expect a large deviation to the experimental conditions, since 
TABLE 2

Summary of sensitivities and LOD. The dilution has been included in all listed LOD. The LOD without dilution would be a factor of 6.7 lower

\begin{tabular}{|c|c|c|c|c|c|}
\hline $\begin{array}{l}\text { Compound } \\
\text { (formula) }\end{array}$ & $m / z(\mathrm{Th})$ & $\begin{array}{l}\text { Sensitivity } \\
\text { (ncps/ppb) }\end{array}$ & $\begin{array}{l}\text { Method LOD } \\
\quad(\mathrm{ppb})\end{array}$ & $\begin{array}{l}\text { Instrument LOD } \\
(\mathrm{ppb})\end{array}$ & $\begin{array}{l}\text { Achievable LOD } \\
\qquad(10 \mathrm{~s})(\mathrm{ppb})\end{array}$ \\
\hline $\begin{array}{l}\text { Hydrogen cyanide } \\
(\mathrm{HCN})\end{array}$ & 28 & 7.5 & $1.36^{* *}$ & 0.06 & 0.037 \\
\hline $\begin{array}{l}\text { Methanol } \\
\left(\mathrm{CH}_{4} \mathrm{O}\right)\end{array}$ & 33 & 15.6 & 4.70 & 0.34 & 0.018 \\
\hline $\begin{array}{l}\text { Hydrogen sulfide } \\
\left(\mathrm{H}_{2} \mathrm{~S}\right)\end{array}$ & 35 & 4.1 & $3.20^{* *}$ & 1.67 & 0.068 \\
\hline $\begin{array}{l}\text { Methyl mercaptan } \\
\left(\mathrm{CH}_{4} \mathrm{~S}\right)\end{array}$ & 49 & $4.0^{*}$ & 1.25 & 0.71 & 0.070 \\
\hline $\begin{array}{l}\text { Nickel carbonyl } \\
\left(\mathrm{Ni}(\mathrm{CO})_{4}\right)\end{array}$ & 105 & 4.7 & 0.53 & 0.23 & 0.059 \\
\hline $\begin{array}{l}\text { Iron carbonyl } \\
\left(\mathrm{Fe}(\mathrm{CO})_{5}\right)\end{array}$ & 197 & 8.1 & 0.93 & 0.10 & 0.034 \\
\hline $\begin{array}{l}\text { Acetone } \\
\left(\mathrm{C}_{3} \mathrm{H}_{6} \mathrm{O}\right)\end{array}$ & 59 & 18.0 & 0.50 & 0.23 & 0.015 \\
\hline $\begin{array}{l}\text { Acetic acid } \\
\left(\mathrm{C}_{2} \mathrm{H}_{4} \mathrm{O}_{2}\right)\end{array}$ & 61 & $8.0 *$ & 1.04 & 0.58 & 0.035 \\
\hline
\end{tabular}

* Sensitivity estimated by proxy, ${ }^{* *}$ see respective discussion $\mathrm{HCN}, \mathrm{H}_{2} \mathrm{~S}$ measurement.

the matrix still consists mainly of $\mathrm{N}_{2}(87 \%)$, with $\mathrm{CO}$ (9\%) and $\mathrm{H}_{2}(4 \%)$. Moreover, sample gas humidity can have an influence on some exceptional compounds, with $\mathrm{HCN}$ and $\mathrm{H}_{2} \mathrm{~S}$ being two. Through the control of the dew-point and the dilution with dry nitrogen, this influence is negligible.

\subsection{Discussion HCN Measurement}

$\mathrm{HCN}$ is a "sticky" compound, i.e. it shows strong surface adsorption effects. When a high concentration of $\mathrm{HCN}$ has been transported in a gas line, it is adsorbed by all wetted surfaces in this system. When the time for equilibration is too short, a change from a low to a high concentration leads therefore to slightly underestimated values, which is relatively insignificant. However, a step from a high concentration to a low concentration (like in blank measurements) results in a relatively high background.

We have estimated the timescale for equilibration of $\mathrm{HCN}$ when switching from streams with high concentrations $(1.5 \mathrm{ppm})$ to one with virtually no $\mathrm{HCN}$. We observe, that the concentration slowly "decays" towards the background concentration. With this setup, we observe decay with two time constants: a fast decay directly after switching from a high to a low concentration with a half-life time of only a few minutes. After several minutes, the decay becomes slower. Assuming an exponential model for those points taken after 25 minutes, we obtain a half-life time of 35 minutes. This adds up to 2 hours for the signal to decay from a high concentration $(1.5 \mathrm{ppm})$ to the background (65 ppt). Therefore an insufficient equilibration after switching leads to an unnecessarily high method LOD. This leaves large room for optimization of the sampling setup, discussed below.

\subsection{Discussion $\mathrm{H}_{2} \mathrm{~S}$ Measurement (Methanol Influence)}

Another discrepancy is found in the LOD for $\mathrm{H}_{2} \mathrm{~S}$. The reason for this is due to interference between different $m / z$. We observe generally high concentrations of methanol. The protonated mass of methanol is $m / z 33.0$ Th. $\mathrm{H}_{2} \mathrm{~S}$ is measured on protonated mass $\mathrm{m} / \mathrm{z} 35.0 \mathrm{Th}$. Due to the naturally occurring isotopes, a small fraction of the methanol signal also shows up on $m / z 35.0$ Th. This means that a methanol signal of $2000 \mathrm{ppb}$ gives a false signal equivalent to $15 \mathrm{ppb}$ of $\mathrm{H}_{2} \mathrm{~S}$. Natural isotopic ratios are well known and can be used for identification of compounds or equivalently to correct for this overlap.

Using the natural isotopic distribution, see Table 3, the contribution of methanol to the $\mathrm{H}_{2} \mathrm{~S}$ signal can be sufficiently corrected for an accurate measurement of $\mathrm{H}_{2} \mathrm{~S}$. 
The residual error is typically negligible. This can be seen in Figure 4, where the methanol signal is displayed with the corrected and uncorrected $\mathrm{H}_{2} \mathrm{~S}$ signal. However, when a very low (i.e. the background) concentration of $\mathrm{H}_{2} \mathrm{~S}$ is to be measured, a residual error in methanol correction leads a large relative error. This contributes significantly to the noise level in the $\mathrm{H}_{2} \mathrm{~S}$ background and therefore deteriorates the method LOD. In PTRinstruments with a high resolution time-of-flight mass detector such interferences are averted [21].

\subsection{Stability}

From the measured data, we can also evaluate the stability of the system. The short term stability of the system can be estimated from the measurement of a stable concentration, e.g. a step in a calibration experiment. We have chosen the HCN calibration as a worst-case

TABLE 3

Natural isotopic distribution of protonated methanol $\left(\mathrm{CH}_{4} \mathrm{OH}^{+}\right)$

\begin{tabular}{c|c}
\hline$m / z(\mathrm{Th})$ & $\%$ \\
\hline 33.0 & 100 \\
\hline 34.0 & 1.12 \\
\hline 35.0 & 0.207 \\
\hline
\end{tabular}

example, since the HCN signal shows strong surface effects and therefore drifts in the data. Table 4 shows mean concentrations of $\mathrm{HCN}$ at different calibrations steps and the relative standard deviation at each step.

\section{Long Term Stability (10 Days)}

The long term stability/reproducibility could be affected by drifts in the instrumental parameters (voltages, transmissions, mass-scale-calibration). To estimate this effect, we compare two calibrations performed at the beginning and end of the measurement campaign.

The calibration performed on 19.10.2009 was a full calibration, while the calibration on 30.10 .2009 consisted only of a quick two-point calibration during the course

TABLE 4

Mean concentration and standard deviation of $\mathrm{HCN}$ in a calibration measurement. The value in the first cell represents the offset value at $m / z 28 \mathrm{Th}$

\begin{tabular}{c|c}
\hline HCN (ppbv) & Rel. standard deviation* \\
\hline $0.6 \pm 0.5$ & \\
\hline $553 \pm 5.0$ & $0.9 \%$ \\
\hline $1504 \pm 13.5$ & $0.9 \%$ \\
\hline
\end{tabular}

* Standard deviation over 20 measurements ( $\sim 50$ minutes).

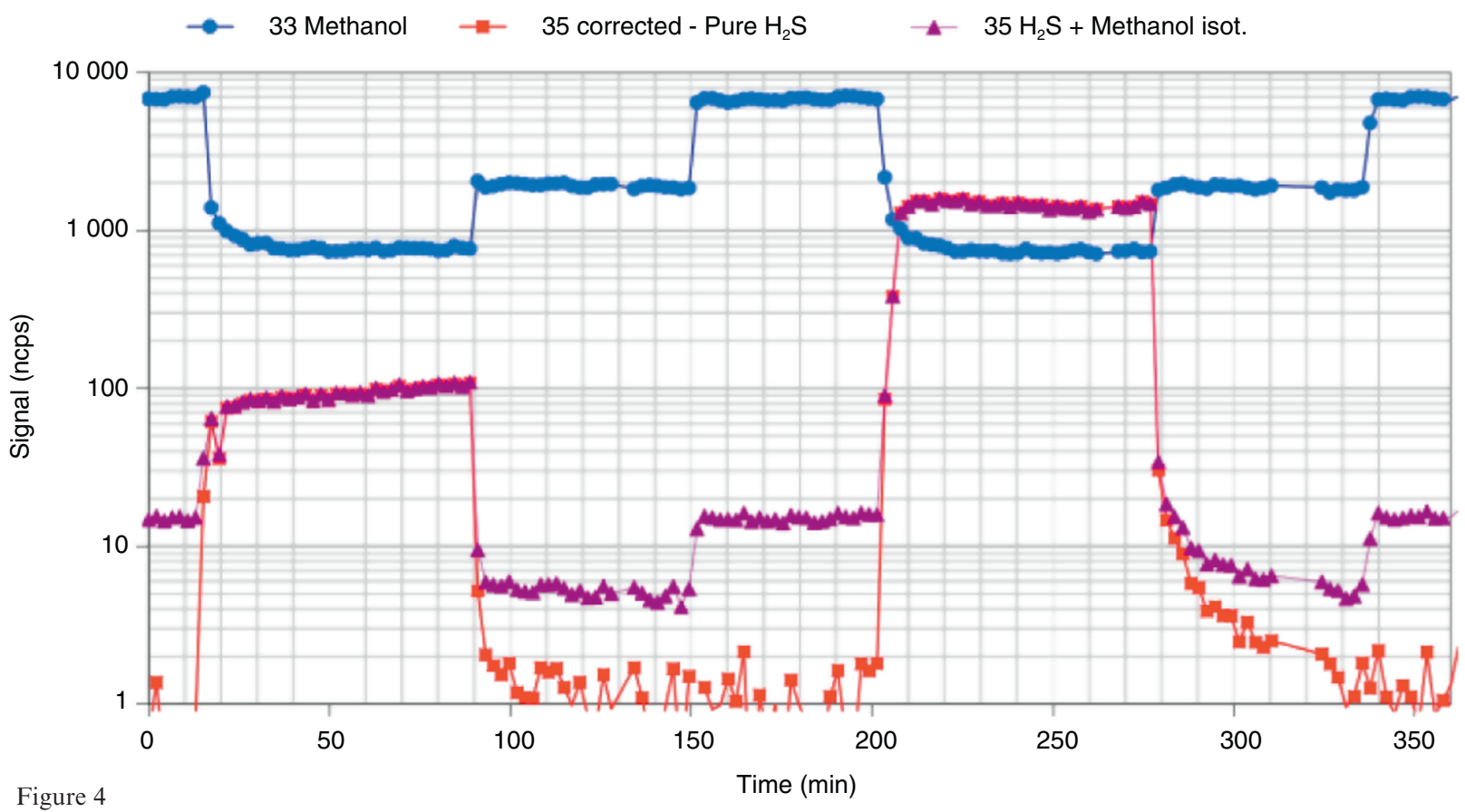

The measurement of $\mathrm{H}_{2} \mathrm{~S}$ is affected by the methanol signal. The isotopic contribution of the methanol signal at $m / z 33$ (circles) has been subtracted from the signal at $m / z 35$ (triangles) to obtain the pure $\mathrm{H}_{2} \mathrm{~S}$ signal (squares). 
of a setup test. Nevertheless, we find excellent agreement $(<3 \%)$ between the results, which demonstrates the stability of the instrumental parameters over this range (see Tab. 5). The higher deviation for acetonitrile is attributed to surface effects and insufficient equilibration in this quick calibration.

\subsection{Monitoring Example}

Figure 5 shows the measured methanol concentration for the different streams. This nicely exemplifies several advantages of the applied method. The concentrations of stream 1 and 2 are significantly different from the concentrations in stream 3 and 4 . We observe a general trend towards higher concentrations downstream of stream 2, indicating that methanol is formed in these process steps. Nevertheless, the trend over time is similar for all, which is not surprising, since they resemble different steps in the same process.

The sudden changes, as are observed on Oct. 22nd and Oct 24th, could be attributed to intentional manipulation of the process, which seem to affect the formation of methanol. This exemplifies the valuable information that can be gained from this continuous monitoring.

\subsection{Filter Break-Through}

Between the sampling points of stream 1 and stream 2, the process gas passes through a filter. As can be seen in Figure 6, we initially observe a working filter, which efficiently reduces the concentration of the measured sulfur compound. After Oct 23rd, we observe the break-through of the filter for this compound. The data has been normalized to the overall maximum. Measurements at stream 3 and 4 (further downstream of the process and not shown in Fig. 6) were below the determined method-LOD, of $1.3 \mathrm{ppb}$. Even after the change over several orders of magnitude in stream 2, we did not observe elevated concentrations in stream 3 or 4 , which demonstrates that we do not have cross-talk between the streams.

TABLE 5

Comparison between two calibrations

\begin{tabular}{c|c|c|c|c}
\hline Compound & $m / z(\mathrm{Th})$ & $\begin{array}{c}\text { Sensitivity } 19.10 .09 \\
(\mathrm{ncps} / \mathrm{ppb})\end{array}$ & $\begin{array}{c}\text { Sensitivity 30.10.09 } \\
\text { (ncps/ppb) }\end{array}$ & Rel. diff. \\
\hline Acetonitrile & 42.0 & 20.4 & 19.8 & $-2.9 \%$ \\
\hline Acetone & 59.0 & 19.1 & 19.2 & $0.4 \%$ \\
\hline Benzene & 79.0 & 10.1 & 9.95 & $0.4 \%$ \\
\hline
\end{tabular}

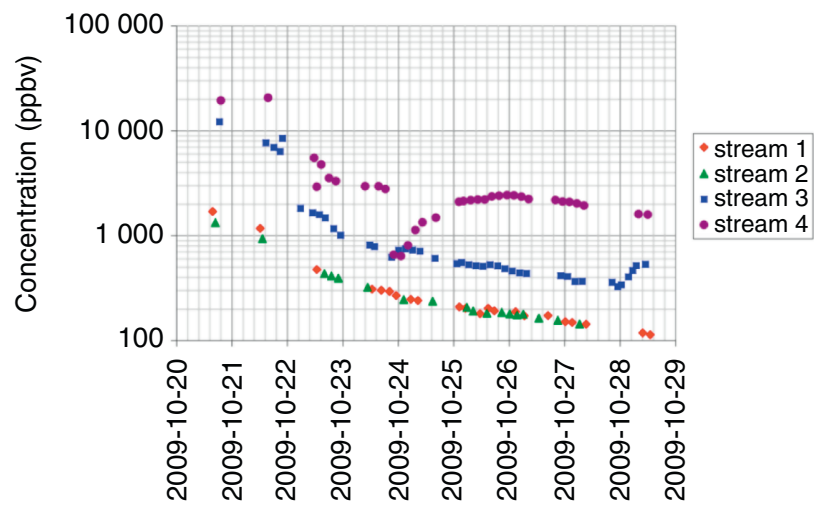

Figure 5

Monitoring of methanol at different gas streams over the course of 8 days.

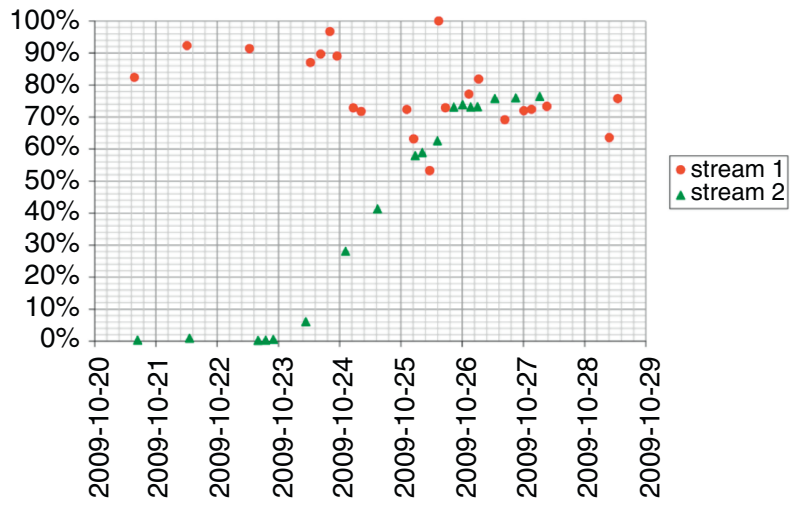

Figure 6

A filter break-through can be observed after the 2009-10-22 for stream 2 while monitoring the concentration of a sulfur compound. Data ( $y$-axis) are normalized to the observed maximum. 


\section{CONCLUSION}

In this study, we have employed PTR-MS for the realtime monitoring of trace compounds in an industrial Fischer-Tropsch process. With minimal modifications, a PTR-MS system could be used to measure trace concentrations of several organic, inorganic and organometallic compounds in syngas. The use of a multiport valve allowed for the multiplexed measurement of trace concentrations at several process steps.

We have thoroughly characterized our system. We found that the stability of the measurement was on the order of $1 \%$, which is more than sufficient. The long term stability (reproducibility) was found to be better than $3 \%$. We found that the LOD for the presented compounds are around or below $1 \mathrm{ppb}$. The limitations in this case were imposed by the experimental setup, since the LOD imposed by the instrument were found to be much lower. Based on the experience gathered in this project, we have been able to compose an optimized setup for this application. This optional box can be connected to the PTR-MS and includes a multiport valve and Silconert ${ }^{\mathrm{TM}} 2000$ treated mass flow controllers, which allow for a fully automated measurement. This system will be a subject of future publications.

Here, we could already show examples, which demonstrate the added value that can be gained by the information from real-time monitoring in such a process. This can be used for safety to detect the formation of toxic compounds. The break through of a filter can easily be detected in its onset, which could be used to protect sensitive parts in the process, like the poisoning of a catalyst. We have also exemplified, that manipulating the process, like changing process parameters, directly reflects in the formation or elimination of volatiles. This information can be used to gain a much deeper understanding of the process and its various steps. Ultimately this could open the door to a new efficiency in process optimization.

\section{ACKNOWLEDGMENTS}

The authors would like to thank Martin Madeira and the site operators for their kind cooperation during the experiments.

\section{REFERENCES}

1 Singer W., Herbig J., Gutmann R., Winkler K., Kohl I., Hansel A. (2011) Applications of PTR-MS in Medicine and Biotechnology, Am. Lab. 43, 7, 34-37.
2 Oudar J. (1980) Sulfur Adsorption and Poisoning of Metallic Catalysts, Catal. Rev.: Sci. Eng. 22, 2, 171-195.

3 Hansel A., Jordan A., Holzinger R., Prazeller P., Vogel W., Lindinger W. (1995) Proton transfer reaction mass spectrometry: online trace gas analysis at the ppb level, Int. J. Mass Spectrom. Ion Process. 149-150, 609-619.

4 Lindinger W., Jordan A. (1998) Proton-transfer-reaction mass spectrometry (PTR-MS): on-line monitoring of volatile organic compounds at pptv levels, Chem. Soc. Rev. 27, 347-375.

5 de Gouw J.A., Middlebrook A.M., Warneke C., Ahmadov R., Atlas E.L., Bahreini R., Blake D.R., Brock C.A., Brioude J., Fahey D.W., Fehsenfeld F.C., Holloway J.S., Le Henaff M., Lueb R.A., McKeen S.A., Meagher J.F., Murphy D.M., Paris C., Parrish D.D., Perring A.E., Pollack I.B., Ravishankara A.R., Robinson A.L., Ryerson T.B., Schwarz J.P., Spackman J.R., Srinivasan A., Watts L. A. (2011) Organic Aerosol Formation Downwind from the Deepwater Horizon Oil Spill, Science 331, 6022, 1295-1299.

6 de Gouw J., Warneke C., Karl T., Eerdekens G., van der Veen C., Fall R. (2007) Measurement of Volatile Organic Compounds in the Earth's Atmosphere using ProtonTransfer-Reaction Mass Spectrometry, Mass Spectrom Rev. 26, 223-257.

7 Tietz M., Buettner A., Conde-Petit B. (2008) Interaction between starch and aroma compounds as measured by proton transfer reaction mass spectrometry (PTR-MS), Food Chem. 4, 108, 1192-1199.

8 Aprea E., Biasioli F., Gasperi F., Märk T.D., van Ruth S. (2006) In vivo monitoring of strawberry flavour release from model custards: effect of texture and oral processing, Flavour Fragr. J. 21, 53-58.

9 Amann A., Poupart G., Telser S., Ledochowski M., Schmid A., Mechtcheriakov S. (2004) Applications of breath gas analysis in medicine, Int. J. Mass Spectrom. 239, 227-233.

10 Herbig J., Amann A. (2009) Proton Transfer ReactionMass Spectrometry Applications in Medical Research, $J$. Breath Res. 3, 020201.

11 Sulzer P., Petersson F., Agarwal B., Becker K.H., Jürschik S., Märk T.D., Perry D., Watts P., Mayhew C.A. (2012) Proton Transfer Reaction Mass Spectrometry and the Unambiguous Real-Time Detection of 2,4,6 Trinitrotoluene, Anal. Chem. 84, 9, 4161-4166.

12 Agarwal B., Petersson F., Jürschik S., Sulzer P., Jordan A., Märk T.D., Watts P., Mayhew C.A. (2011) Use of proton transfer reaction time-of-flight mass spectrometry for the analytical detection of illicit and controlled prescription drugs at room temperature via direct headspace sampling, Anal. Bioanal. Chem. 400, 2631-2639.

13 Shimono A., Naganuma M. (2005) Real-time VOC monitoring using PTR-MS emitted from hazardous waste incinerator flue gas, 2nd PTR-MS Conference, Obergurgl, Austria, 29 Jan.-3 Feb.

14 Available at: http://www.ionicon.com/downloads/cleanroom.pdf

15 Agarwal B., Jürschik S., Sulzer P., Petersson F., Jaksch S., Jordan A., Märk T.D. (2012) Detection of isocyanates and polychlorinated biphenyls using proton transfer reaction mass spectrometry, Rapid Commun. Mass Spectrom. 26, 983-989. 
16 Wang Z., Yang J., Li Z., Xiang Y. (2009) Syngas composition study, Frontiers Energy 3, 3, 369-372.

17 Available at: http://www.silcotek.com/silcod-technologies/ SilcoNert-inert-coating/

18 Available at: http://www.ionicon.com/downloads/ facts_HS_PTR-MS.pdf

19 Singer W., Beauchamp B., Herbig J., Dunkl J., Kohl I., Hansel A. (2007) Dynamic Gas Dilution System for Accurate Calibration of Analytical Instruments such as PTRMS, 3rd International Conference on Proton Transfer Reaction Mass Spectrometry and its Applications, Obergurgl, Austria, 27 Jan.-1 Feb., http://www.uibk.ac.at/iup/ buch_pdfs/978-3-902719-88-1.pdf
20 Beauchamp J., Herbig J., Dunkl J., Singer W., Hansel A. (2013) Dynamic gas calibration of a proton-transfer-reaction mass spectrometer at varying humidity and carbon dioxide conditions (in preparation).

21 Graus M., Müller M., Hansel A. (2010) High Resolution PTR-TOF: Quantification and Formula Confirmation of VOC in Real Time, J. Am. Soc. Mass Spectrom. 21, 6, 1037-1044.

Manuscript accepted in November 2012

Published online in August 2013 